\title{
Effect of the rights of intellectual property on the export revenues ${ }^{1}$
}

\section{Fikri mülkiyet haklarının ihracat gelirleri üzerindeki etkisi}

\author{
Sedat Durmuşkaya ${ }^{2}$ \\ Ahmet Yağmur Ersoy ${ }^{3}$
}

\begin{abstract}
Therise of export revenues in Turkey in the recent years, have been possible to come up with factors that effecting export at the same time and in a positive way. In addition to many studies that aimed which factors effect therise of export revenues and its direction, in this study, exportand the rights of intellectual property, in particular the causality relation of the rights of industrial property were investigated.

Some of the industrial property rights of Industrial Design, Utility Model, Trade Mark and Patent aplicant numbers are used as a data set in the analysis in order to investigate this effect quantitatively. Toda-Yamamoto casuality process that particularly gives successful results in the small sample sets is used to reveal the existence of the relationship that mentioned.

According to results by obtaining from analysis, while a causal relation was determined from industrial designs and aplicant number of utility models to export, bidirectional causality relation was identified between trademark applications and patent applications and export. This results reveal the importance of protection of intellectual property rights in a beterway to ensure more export growth.
\end{abstract}

Keywords: The Rights of Intellectual Property, Causalty, Toda- Yamamoto.

(Extended English abstract is at the end of this document)
Özet

Türkiye ihracat gelirlerinde son dönemlerde yaşanan artss, ihracata etki eden faktörlerin aynı anda ve olumlu bir şekilde bir araya gelmesi ile mümkün olmuştur. İhracat gelirlerinin artışına etki eden faktörlerin neler olduğuna ve ne yönde etkilediğine yönelik yapılan birçok çalışmaya ek olarak bu çalışmada, ihracat ve fikri mülkiyet hakları, özelde ise sınai mülkiyet hakların arasındaki nedensellik ilişkisi araştırılmıştur.

Bu etkinin nicel olarak araştırılabilmesi için sınai mülkiyet haklarından olan Endüstriyel Tasarım, Faydalı Model, Marka ve Patent başvuru sayıları analizlerde veri seti olarak kullanılmıştır. Bahsedilen ilişkinin varlı̆̆ını ortaya koyabilmek için özellikle küçük örneklem setlerinde başarılı sonuçlar veren Toda-Yamamoto nedensellik süreci kullanılmıştır.

Yapılan analizlerden elde edilen sonuçlara göre, endüstriyel tasarım ve faydalı model başvuru sayılarından ihracat'a doğru bir nedensellik ilisskisi saptanırken, marka başvuruları ve patent başvuruları ile ihracat arasında çift yönlü nedensellik ilişkisi saptanmıştır. Bu sonuçlar daha çok ihracat artışı sağlamak için fikri mülkiyet haklarının daha iyi bir şekilde korunması gerektiğinin önemini ortaya koymaktadir.

Anahtar Kelimeler: Fikri Mülkiyet Hakları, Nedensellik, Toda-Yamamoto.

\footnotetext{
1 The study is presented at $25^{\text {th }}$ August 2015 as a proceeding in the $7^{\text {th }}$ International Balkan Social Sciences Congress held in Kaposvar/Hungary.

2 Asst. Prof. Dr., University of Sakarya, Vocational School of Karasu, sdurmuskaya@sakarya.edu.tr

${ }^{3}$ Asst. Prof. Dr., University of Sakarya, Faculty of Business, Department of International Trade, ayersoy@sakarya.edu.tr
} 
Durmuşkaya, S., \& Ersoy, A. Y. (2016). Fikri mülkiyet haklarının ihracat gelirleri üzerindeki etkisi. International Journal of Human Sciences, 13(1), 798-808. doi:10.14687/ijhs.v13i1.3599

\section{Giriş}

Gelişmiş ülkelerle gelişmekte olan ülkeler arasındaki refah fark1, ülkelerin başlangıçtan beri tesis ettikleri ekonomik ve sosyal kurumların oluşturulması ve yürütülmesiyle ilgili olarak ortaya çıkmaktadır. Ekonomik refahın sağlanmasında elbette ki ekonomik düzen tek başına yeterli değildir. Mevcut üretim yapılanmasının siyasi faktörlerle de desteklenmesi gerekmektedir. Sanayi Devrimi'nden itibaren Batı Dünya'sında hakim olan kapitalist sistemin belki de en önemli özelliği mülkiyet hakkını güvence altına almış olmasıdır. Üretim bağlamında mülkiyet kavramını sınai ve fikri mülkiyet unsurları ile ilişkilendirebiliriz. Üretimin arttırabilmesi ancak fertlerin ürettikleri değerlerden kendi paylarına düşeni alabileceklerine ikna olmalarıyla sağlanabilir.

Üretimde bir artış sağlamak her zaman tek başına yeterli olmayabilir. Ülkenin zenginlik düzeyi özellikle, o ülkenin net diş alem gelirleri ile ilgilidir. Bu anlamda ülkenin ihracat gelirlerinin ithalat giderlerinden fazla olması gerektiği açıktır. Tam da günümüz kapitalist sistemi içerisinde rekabetin yeni kuralları kendisini göstermeye başlamıştır. Üretimde standart ürün ve kitle üretimi yerini spesifik, standart dışı ve katma değeri yüksek ürünlere devretmektedir. Küresel ekonomik sistem varolanın güncellenmesini değil yeni fikirlerin çoğalmasını teşvik etmektedir. Küresel iletişim ağlarının üretim yapılarının birbirine bağlamasıyla sistem, karşılıklı güvene ve güvenin kurumsallaştırılmasına doğru bir dönüşüm göstermektedir. Thomas Friedman'ın ${ }^{4}$ öne sürdüğü gibi dünya düzleşmektedir ve bu düzleşme içerisinde fertlerin mülkiyet haklarının korunması daha da önemli hale gelmiştir.

Fikri mülkiyet kavramı, fikir ile oluşturulan; buluşların, edebi eserlerin, sanat eserlerinin, sembollerin, isimlerin, resimlerin ve tasarımların ticarette kullanılmasını ifade etmektedir.(WIPO: 2014) Fikri mülkiyet kavramı; sınai mülkiyet ve edebi mülkiyet olarak iki başlık altında incelenmektedir. Sınai mülkiyet patent, faydalı model, tasarım, marka ve coğrafi işaretleri belirtirken; edebi mülkiyet sanat ve edebiyat eserleri ve bunların yayın haklarılla ilgilenmektedir. Endüstriyel gelişimin rekabeti sağlayan bir unsur olarak görülmesinden dolayı, sınai mülkiyetin geliştirilip, korunması daha önem verilen bir husus olmuştur. Fikri mülkiyet kavramı Avrupa'da 15.yy' da kendinden ilk kez söz ettirirken; ülkemiz açısından bu kavram ilk kez 19.yy'ın başlarında (Osmanlı İmparatorluğu'nun son dönemlerinde) karşımıza çıkmaktadır. Bununla birlikte ülkemiz, AB uyumu süreci ile 1996 yılından sonra fikri mülkiyet ile ilgili çalışmalarda önemli ilerlemeler kaydetmiştir.

Fikri Mülkiyet ile ilgili uluslararası anlaşmalara göz atarsak; 1883 yllında 11 ülkenin (Belçika, Brezilya, Guatemala, El Salvador, Fransa, Hollanda, İtalya, Sırbistan, İspanya, İsviçre ve Portekiz) katılımıyla imzalanan Paris Sözleşmesi'nin 2014 itibariyle üye sayısı 176'dir (WIPO:2014). Bu anlaşma fikri mülkiyet haklarının korunmasını amaçlayan ve oluşturulan ilk uluslararası anlaşma niteliğindedir.Daha sonra 1967 yllinda kurulan ve üye sayısı bugün itibariyle 188 ülkeye ulaşan Dünya Fikri Mülkiyet Haklanı Anlaşması (WIPO) imzalanmıştır. 1994 yılında da Ticaretle Bağlantılı Fikri Mülkiyet Hakları Anlaşması (TRIPS) ile uluslararası düzeyde uyumlaşma büyük ölçüde sağlanmıştır (WIPO:2014).

Bu kanunlar ve uluslararası anlaşmalar yoluyla koruma altına alınan fikri mülkiyet hakları, hem ülke içindeki yatırımları hem de doğrudan yabancı yatırımları çekici hale getirecektir. Çünkü ticaret ve fikri mülkiyet hakları arasında bir ilişki söz konusu olduğu düşünülmektedir. Örneğin sınai haklardan biri olan patentin korunması inovasyonu arttıracaktır. İnovasyon gelişirse firmalar başka pazarlara açılma isteği duyarlar. Bu da ticaretin gelişmesine ve büyümeye yol açacaktır (Segerstrom: 1991). Böylece inovasyonun gücü fikri mülkiyet haklarının korunması için teşvik sağlayacaktır ( Park ve Lippoldt: 2004).

\footnotetext{
${ }^{4}$ Thomas L. Friedman, “Dünya Düzdür - Yirmi Birinci Yüzyılın Kısa Tarihi”, Boyner Yayınları, İstanbul, 2006
} 
Diğer yandan sınai fikri mülkiyet hakları ve ekonomik faaliyetler üzerine yapılmış olan bazı araştırmalara değinecek olursak;

Seyoum (1996): Kuzey Amerika, Latin Amerika, Avrupa, Orta Doğu ve Asya'da bulunan 27 ülke ile 1975-1990 yılları için gerçekleştirdiği araştırmada fikri mülkiyet haklarının korunmasının yatırımı ve dolayısıyla yurtiçi hasılayı arttırdığını ortaya koymuştur. Araştırma sonucunda az gelişmiş ülkelerde patent ve yatırım arasında bir ilişkisi bulunmamasına rağmen fikri mülkiyet hakları yatırım çekmek için bir teşvik unsuru olarak ifade edilmektedir.

Gould ve Gruben (1996): yaptıkları çalışmada patent koruması, ticaret rejimi ve ülkenin karakteristiğinin ekonomik büyümeye etkisinin olduğu,ayrıca fikri mülkiyet haklanı korumasının yüksek olmasının, ekonomik büyüme oranlarını da yükselttiği sonucuna varmışlardır.

Montobbio ve Rampa (2005): Arjantin, Brezilya, Çin, Kolombiya, Hindistan, Malezya, Meksika, Singapur ve Tayland örneği ile, gelişmekte olan ülkelerde 1985-1998 yılları arasında 25 sektörde yapılan patent başvurularını ve bu ülkelerin ihracat oranlarını karşılaştırmışlardır. Araştırma sonucunda teknolojik gelişme ve büyüme arasında pozitif yönlü bir ilişkiye ulaşılmıştur.

Schneider(2005) ise: araştırmasında inovasyon ve büyüme temelinde gelişmiş ve gelişmekte olan ülkeleri incelemeye almıstır. Bu araştırma sonucunda inovasyon ve büyümenin fikri mülkiyet ve yatırımları geliştirdiği sonucuna varılmıştır.

Chen ve Puttitanun (2005): taklitten vazgeçilmesinin gelişmekte olan ülkeler açısından yerel gelişimin desteklenmesinde ne kadar etkili olduğunu inceledikleri çalışmalarında, gelişmekte olan 64 ülkede fikri mülkiyet haklarının ekonomik büyüme ve kalkınma üzerinde pozitif etkiye sahip olduğu sonucuna ulaşmışlardır.

Türkiye özelinde gerçekleştirilen bazı araştırmaların sonuçlarına bakacak olursak;

Bozkurt (2008): araştırmasında sektörel patent tescilleri ve sektörel ihracat performansları arasındaki ilişkiyi incelemiştir ve 1985-2001 veri setinde pozitif anlamlı bir ilişki olduğunu sonucuna ulaşmışır.

Özer ve Çiftçi'nin: gerçekleştirdikleri araştırmada ise Ar-Ge harcamaları ile mamül ürün ihracatının pozitif yönlü ilişki içinde olduğu ve Ar-Ge faaliyetlerinin yeni tasarım üretip ihraç etmekte anlamlı olduğu sonucuna ulaşılmıştır. Bunun yanında Ar-Ge harcamalarındaki artışın bilgi ve teknoloji ihracatını da arttırdığı ve Ar-Ge harcamalarındaki artışın ileri teknoloji ihracatını da arttırdığı ifade edilmiştir.

Uzay, Demir ve Yildırım (2012): araştırmalarında 1995-2005 yılları arasında Türk imalat sektöründe yapılan ihracat ve Ar-Ge harcamalarının ihracat etkisiincelenmiştir. Bunun sonucunda etkinin gecikmeli olarak ortaya çıtı̆̆g sonucuna varılmıştır.

Yıldırım ve Kesikoğlu(2012): araştırmalarında Ar-Ge harcamaları ve ihracat ilişkisini incelemişlerdir. 1996-2008 yılları arasında 25 alt sektörün analizini yapan çalışmada Ar-Ge harcamalarının ihracatı arttırıcı etkisi olduğu sonucuna varılmıştır.

Göçer (2013): 11 Asya ülkesi üzerinde 1996-2012 dönemlerini baz alarak yaptığ1 araştırmada Ar-Ge ve ekonomik büyüme arasında pozitif yönde bir ilişki bulmuştur. Ar-Ge harcamaları ve ekonomik büyümeyeilaveten yüksek teknoloji içeren ürünlerin payı, bilgi ve iletişim teknolojilerinin payı gibi değişkenlerin de dikkate alındığı çalışmada; Ar-Ge harcamalarında ortaya çıkacak \%1 lik bir artışın, ekonomik büyümede \%40 lıkbir artısaneden olduğu sonucuna ulaşılmıştur. 
Durmuşkaya, S., \& Ersoy, A. Y. (2016). Fikri mülkiyet haklarının ihracat gelirleri üzerindeki etkisi. International Journal of Human Sciences, 13(1), 798-808. doi:10.14687/ijhs.v13i1.3599

Son olarak Kılıç ve Çınar (2014): araştırmasında ise 23 işletmeyle anket tekniği uygulanmış olup ihracat performansı ile orijinal marka ve orijinal tasarım arasında anlamlı bir ilişki olduğunu ifade edilmiştir.

\section{VERİ SETİ VE METODOLOJİ}

İhracat ile endüstriyel tasarım, faydalı model, marka ve patent başvuru sayısı arasındaki nedensellik ilişkisini ortaya koymaya çalışan bu çalışmada, 2009 Ocak ayı ve 2015 Mart ayları arasında yer alan 75 aylık veri seti kullanılmıştır. İhracat rakamlarına ilişkin veriler Türkiye İstatistik Kurumu’na (TÜIK) ait web sitesinden ve endüstriyel tasarım, faydalı model, marka ve patent başvuru sayısına ilişkin veriler ve Türk Patent Enstitüsü’ne (TPE) ait web sitelerinden elde edilmiştir.

TPE' ne ait veriler başvuru sayısı bakımından aylık olarak yerli ve yabancı başvuru sayılarının toplamını ifade etmektedir. Bu verileri toplam olarak alınmasının temel nedeni, hem yerli hem de yabancı yatırımcıların Türkiye sınırları içerisinde faaliyette bulunarak, ihracat rakamlarına etki edeceği düşüncesidir.

Küçük örneklem setlerinin analizinde daha doğru sonuçlar vermesi bakımından çalışmada değişkenler arasındaki nedensellik ilişkisini ortaya koyabilmek için Toda-Yamamoto (1995) nedensellik testi, E-views 7.0 ve Excell programları yardımı ile yapılmıştır.

$\mathrm{Bu}$ metod, bir VAR modeli parametrelerinin anlamlılığını testinde yararlanılan modifiye edilmiş Wald testini kullanmaktadır. Toda ve Yamamoto'ya göre modifiye edilmiş Wald istatistiği, serilerin $\mathrm{I}(0), \mathrm{I}(1)$ veya $\mathrm{I}(2)$ kombinasyonlarnna veya herhangi bir seviyede entegre olsa da veya olmasa da uygulanabilmektedir (Altuntaş,2013:13). Toda-Yamamato nedensellik testinde önemli olan, VAR modelin gecikme uzunluğu $(\mathrm{k})$ ve incelenen serilerin en büyük durağanlık mertebesidir $\left(\mathrm{d}_{\max }\right)$. Bu iki değer belirlendikten sonra $\left(k+d_{\max }\right)$ boyutunda bir VAR model kurularak, Toda-Yamamato testi gerçekleştirilebilir.

Ancak modele sonradan ilave edilen terimlerin katsayılanı dikkate alınmaz. Bu nedensellik prosedüründe entegrasyon mertebesinin $\left(\mathrm{d}_{\max }\right)$, VAR modelinin gerçek mertebesini $(\mathrm{k})$ aşmaması gerekmektedir (Akar,2008:189). Bu itibarla çalışmada kullanılmış olan VAR modelleri sırasıyla eşitlik 1'den 8'e kadar görülen modeller şeklinde oluşturulmuştur.

$$
\begin{aligned}
& \tilde{I} H R_{\mathrm{t}}=\alpha_{10}+\sum_{i=1}^{k} \alpha_{1 \mathrm{i}} \operatorname{TAS}_{\mathrm{t}-\mathrm{i}}+\sum_{\mathrm{i}=1}^{k} \beta_{1 \mathrm{I}} \mathrm{I} H R_{\mathrm{t}-\mathrm{i}}+\sum_{j=k+1}^{d \max } \delta_{1 \mathrm{i}} \operatorname{TAS}_{\mathrm{t}-\mathrm{i}}+\sum_{j=k+1}^{d \max } \lambda_{1 \mathrm{i}} \mathrm{I} H R_{\mathrm{t}-\mathrm{i}}+\varepsilon_{1 \mathrm{t}}
\end{aligned}
$$

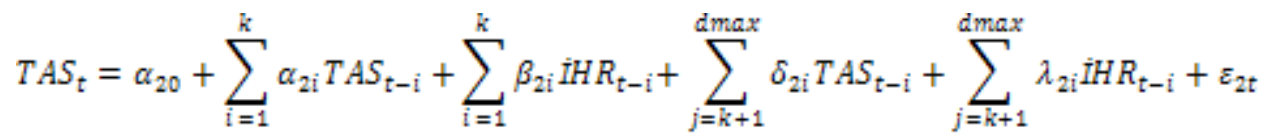

$$
\begin{aligned}
& \tilde{I} H R_{\mathrm{t}}=\alpha_{10}+\sum_{\mathrm{i}=1}^{k} \alpha_{1 \mathrm{i}} F A Y_{\mathrm{t}-\mathrm{i}}+\sum_{\mathrm{i}=1}^{k} \beta_{1 \mathrm{i}} \mathrm{I} H R_{\mathrm{t}-\mathrm{i}}+\sum_{j=k+1}^{d \max } \delta_{1 \mathrm{i}} F A Y_{\mathrm{t}-\mathrm{i}}+\sum_{j=k+1}^{d \max } \lambda_{1 \mathrm{i}} \mathbf{I} H R_{\mathrm{t}-\mathrm{i}}+\varepsilon_{1 \mathrm{t}} \\
& F A Y_{\mathrm{t}}=\alpha_{20}+\sum_{\mathrm{i}=1}^{k} \alpha_{2 \mathrm{i}} F A Y_{\mathrm{t}-\mathrm{i}}+\sum_{\mathrm{i}=1}^{k} \beta_{2 \mathrm{i}} \mathrm{I} H R_{\mathrm{t}-\mathrm{i}}+\sum_{j=k+1}^{d \max } \delta_{2 \mathrm{i}} F A Y_{\mathrm{t}-\mathrm{i}}+\sum_{j=k+1}^{d \max } \lambda_{2 \mathrm{i}} \mathrm{I} H R_{\mathrm{t}-\mathrm{i}}+\varepsilon_{2 \mathrm{t}}
\end{aligned}
$$


Durmuşkaya, S., \& Ersoy, A. Y. (2016). Fikri mülkiyet haklarının ihracat gelirleri üzerindeki etkisi. International Journal of Human Sciences, 13(1), 798-808. doi:10.14687/ijhs.v13i1.3599

$$
\begin{aligned}
& \tilde{I} H R_{t}=\alpha_{10}+\sum_{i=1}^{k} \alpha_{1 i} M A R_{t-i}+\sum_{i=1}^{k} \beta_{1 i} \tilde{I} H R_{t-i}+\sum_{j=k+1}^{d \max } \delta_{1 i} M A R_{t-i}+\sum_{j=k+1}^{d m a x} \lambda_{1 i} I H R_{t-i}+\varepsilon_{1 t} \\
& M A R_{\mathrm{t}}=\alpha_{20}+\sum_{\mathrm{i}=1}^{k} \alpha_{2 \mathrm{i}} M A R_{\mathrm{t}-\mathrm{i}}+\sum_{\mathrm{i}=1}^{k} \beta_{2 \mathrm{i}} \mathrm{I} H R_{\mathrm{t}-\mathrm{i}}+\sum_{j=\mathrm{k}+1}^{d \max } \delta_{2 \mathrm{i}} M A R_{\mathrm{t}-\mathrm{i}}+\sum_{j=\hat{i}+1}^{d \max } \lambda_{2 \mathrm{i}} \mathrm{i} H R_{\mathrm{t}-\mathrm{i}}+\varepsilon_{2 \mathrm{t}} \\
& \tilde{I} H R_{\mathrm{t}}=\alpha_{10}+\sum_{\mathrm{i}=1}^{k} \alpha_{1 \mathrm{i}} P A T_{\mathrm{t}-\mathrm{i}}+\sum_{\mathrm{i}=1}^{k} \beta_{1 \mathrm{i}} \mathrm{I} H R_{\mathrm{t}-\mathrm{i}}+\sum_{j=k+1}^{\text {dmax }} \delta_{1 \mathrm{i}} P A T_{\mathrm{t}-\mathrm{i}}+\sum_{j=k+1}^{\text {dmax }} \lambda_{1 \mathrm{i}} \mathbf{I} H R_{\mathrm{t}-\mathrm{i}}+\varepsilon_{1 \mathrm{t}} \\
& P A T_{\mathrm{t}}=\alpha_{20}+\sum_{\mathrm{i}=1}^{k} \alpha_{2 \mathrm{i}} P A T+\sum_{\mathrm{i}=1}^{k} \beta_{2 \mathrm{i}} \mathrm{I} H R_{\mathrm{t}-\mathrm{i}}+\sum_{j=k+1}^{d \max } \delta_{2 \mathrm{i}} P A T_{\mathrm{t}-\mathrm{i}}+\sum_{j=k+1}^{d m a x} \lambda_{2 \mathrm{i}} \mathrm{I} H R_{\mathrm{t}-\mathrm{i}}+\varepsilon_{2 \mathrm{t}}
\end{aligned}
$$

Toda-Yamamato nedensellik testi yapılabilmesi için serilerin durağanlık mertebesinin bilinmesi gerekmektedir. Bunun için Dickey-Fuller tarafindan geliştirilmiş Augmented Dickey-Fuller (ADF) testi ile birim kök testi yapılarak serilerin durağanlığı sınanmıştır. Tablo 1, Toda-Yamamato nedensellik testi için ADF birim kök testi sonuçlarını göstermektedir.

Tablo 1: ADF Birim Kök Test Sonuçları

\begin{tabular}{|l|c|c|c|c|c|c|}
\hline & \multicolumn{2}{|c|}{ Sabitsiz ve Trendsiz } & \multicolumn{2}{c|}{ Sabitli } & \multicolumn{2}{c|}{ Sabitli ve Trendli } \\
\hline $\begin{array}{l}\text { Augmented } \\
\text { Dickey-Fuller } \\
\text { Test Ttatistic }\end{array}$ & t-Statistic & Prob. & t-Statistic & Prob. & t-Statistic & Prob. \\
\hline IHR & 1.760 .180 & 0.9802 & -1.745 .745 & 0.4037 & 0.454236 & 0.9990 \\
\hline$\Delta \dot{I H R}$ & -2.006 .334 & $0.0437^{* *}$ & -9.613 .114 & $0.0000^{*}$ & -4.659 .378 & $0.0020^{*}$ \\
\hline TAS & 1.899 .200 & 0.9854 & -1.923 .584 & 0.3196 & 0.552872 & 0.9993 \\
\hline$\triangle T A S$ & -4.273 .203 & $0.0000^{*}$ & -8.526 .237 & $0.0000^{*}$ & -9.077 .492 & $0.0000^{*}$ \\
\hline FAY & 1.362 .050 & 0.9552 & -1.493 .179 & 0.5306 & -0.543267 & 0.9788 \\
\hline$\triangle F A Y$ & -4.315 .301 & $0.0000^{*}$ & -8.330 .080 & $0.0000^{*}$ & -8.543 .032 & $0.0000^{*}$ \\
\hline$M A R$ & 1.145 .939 & 0.9335 & -4.395 .635 & $0.0007^{*}$ & -5.057 .990 & $0.0005^{*}$ \\
\hline$\triangle M A R$ & -2.701 .596 & $0.0076^{*}$ & - & - & - & - \\
\hline PAT & 3.628 .923 & 0.9999 & -2.600 .606 & 0.0982 & 0.310192 & 0.9983 \\
\hline$\triangle P A T$ & -2.404 .385 & $0.0168^{* *}$ & -3.777 .165 & $0.0051^{* * *}$ & -8.823 .978 & $0.0000^{*}$ \\
\hline
\end{tabular}

$* \% 1$ Seviyesinde anlaml, $* * 0 \% 5$ Seviyesinde anlaml, $* * * \% 10$ Seviyesinde anlamlı

Tablo 1' de görüleceği üzere modellerde yer alan tüm değişkenler \%5 anlam düzeyinde sabitli, sabitli ve trendli ve sabitsiz trendsiz modelde durağanlık mertebeleri $\mathrm{I}(1)\left(\mathrm{d}_{\max }=1\right)$ çıkmıştır. Ancak marka değişkeni sabitli, sabitli ve trendli modelde düzeyde $\mathrm{I}(0)\left(\mathrm{d}_{\max }=0\right)$ çıkmıştır.

Daha sonra VAR modellerinin gecikme uzunluklarının belirlenmesinde (LR) Sequential modified LR test statistic ,(FPE) Final prediction error, (AIC) Akaike information criterion, (SC) Schwarz information criterion, (HQ) Hannan-Quinn information criterion bilgi kriteri kullanılmış ve gecikme uzunlukları ise Tablo 2,3,4 ve 5’te yer almaktadır. 
Durmuşkaya, S., \& Ersoy, A. Y. (2016). Fikri mülkiyet haklarının ihracat gelirleri üzerindeki etkisi. International Journal of Human Sciences, 13(1), 798-808. doi:10.14687/ijhs.v13i1.3599

Tablo 2: İhracat - Endüstriyel Tasarım Uygun Gecikme Uzunluğu

\begin{tabular}{|c|c|c|c|c|c|}
\hline Lag & LR & FPE & AIC & SC & HQ \\
\hline 0 & NA & $1.75 \mathrm{e}+18$ & 47.68098 & 47.74626 & 47.70685 \\
\hline 1 & 63.50415 & $7.40 \mathrm{e}+17$ & 46.82164 & 47.01748 & 46.89924 \\
\hline 2 & 23.28987 & $5.76 \mathrm{e}+17$ & 46.56961 & $46.89601 *$ & 46.69894 \\
\hline 3 & 6.940494 & $5.78 \mathrm{e}+17$ & 46.57348 & 47.03044 & 46.75454 \\
\hline 4 & 14.60175 & $5.09 \mathrm{e}+17$ & 46.44364 & 47.03116 & 46.67643 \\
\hline 5 & $19.89272 *$ & $4.05 \mathrm{e}+17$ & 46.21229 & 46.93037 & $46.49681 *$ \\
\hline 6 & 8.527111 & $3.91 \mathrm{e}+17 *$ & $46.17490 *$ & 47.02354 & 46.51116 \\
\hline 7 & 5.152502 & $4.02 \mathrm{e}+17$ & 46.19533 & 47.17452 & 46.58332 \\
\hline
\end{tabular}

LR: sequential modified LR test statistic ,FPE: Final prediction error, AIC: Akaike information criterion, SC: Schwarz information criterion, HQ:Hannan-Quinn information criterion

Tablo 3: İhracat - Faydalı Model Uygun Gecikme Uzunluğu

\begin{tabular}{|c|c|c|c|c|c|}
\hline Lag & LR & FPE & AIC & SC & HQ \\
\hline 0 & NA & $5.25 \mathrm{e}+15$ & 41.87335 & 41.93863 & 41.89922 \\
\hline 1 & 74.60144 & $1.88 \mathrm{e}+15$ & 40.84328 & 41.03912 & 40.92088 \\
\hline 2 & 22.60082 & $1.47 \mathrm{e}+15$ & 40.60219 & $40.92859 *$ & 40.73152 \\
\hline 3 & 7.993911 & $1.46 \mathrm{e}+15$ & 40.58879 & 41.04575 & 40.76985 \\
\hline 4 & 11.27477 & $1.36 \mathrm{e}+15$ & 40.51534 & 41.10285 & 40.74813 \\
\hline 5 & $11.09550^{*}$ & $1.26 \mathrm{e}+15^{*}$ & $40.43833^{*}$ & 41.15640 & $40.72285^{*}$ \\
\hline 6 & 4.697543 & $1.30 \mathrm{e}+15$ & 40.47056 & 41.31920 & 40.80682 \\
\hline 7 & 1.034495 & $1.45 \mathrm{e}+15$ & 40.56869 & 41.54789 & 40.95668 \\
\hline
\end{tabular}

LR: sequential modified LR test statistic ,FPE: Final prediction error, AIC: Akaike information criterion, SC: Schwarz information criterion, HQ:Hannan-Quinn information criterion

Tablo 4: İhracat - Marka Uygun Gecikme Uzunluğu

\begin{tabular}{|c|c|c|c|c|c|}
\hline Lag & LR & FPE & AIC & SC & HQ \\
\hline 0 & NA & $8.73 \mathrm{e}+18$ & 49.28945 & 49.35473 & 49.31531 \\
\hline 1 & 86.08288 & $2.61 \mathrm{e}+18$ & 48.08274 & 48.27858 & 48.16034 \\
\hline 2 & 21.01347 & $2.11 \mathrm{e}+18$ & 47.86684 & $48.19324 *$ & 47.99617 \\
\hline 3 & $14.94966^{*}$ & $1.86 \mathrm{e}+18$ & 47.73941 & 48.19637 & $47.92047^{*}$ \\
\hline 4 & 9.137187 & $1.79 \mathrm{e}+18$ & 47.70219 & 48.28971 & 47.93498 \\
\hline 5 & 8.153677 & $1.75 \mathrm{e}+18^{*}$ & $47.67679 *$ & 48.39487 & 47.96132 \\
\hline 6 & 5.205790 & $1.80 \mathrm{e}+18$ & 47.69979 & 48.54842 & 48.03604 \\
\hline 7 & 4.219489 & $1.88 \mathrm{e}+18$ & 47.73782 & 48.71702 & 48.12581 \\
\hline
\end{tabular}

LR: sequential modified LR test statistic ,FPE: Final prediction error, AIC: Akaike information criterion, SC: Schwarz information criterion, HQ:Hannan-Quinn information criterion

Tablo 5: İhracat - Patent Uygun Gecikme Uzunluğu

\begin{tabular}{|c|c|c|c|c|c|}
\hline Lag & LR & FPE & AIC & SC & HQ \\
\hline 0 & NA & $4.17 \mathrm{e}+16$ & 43.94569 & 44.01096 & 43.97155 \\
\hline 1 & 61.59267 & $1.82 \mathrm{e}+16$ & 43.11575 & 43.31159 & 43.19335 \\
\hline 2 & 22.35232 & $1.44 \mathrm{e}+16$ & 42.87860 & 43.20500 & 43.00793 \\
\hline 3 & 15.79682 & $1.25 \mathrm{e}+16$ & 42.73728 & 43.19424 & 42.91834 \\
\hline 4 & 18.11741 & $1.03 \mathrm{e}+16$ & 42.54786 & $43.13537 *$ & $42.78065^{*}$ \\
\hline 5 & $9.537594^{*}$ & $9.87 \mathrm{e}+15^{*}$ & $42.49818^{*}$ & 43.21625 & 42.78270 \\
\hline 6 & 3.898598 & $1.04 \mathrm{e}+16$ & 42.54494 & 43.39358 & 42.88120 \\
\hline 7 & 6.631587 & $1.04 \mathrm{e}+16$ & 42.53746 & 43.51666 & 42.92545 \\
\hline
\end{tabular}

LR: sequential modified LR test statistic ,FPE: Final prediction error, AIC: Akaike information criterion, SC: Schwarz information criterion, HQ:Hannan-Quinn information criterion 
Durmuşkaya, S., \& Ersoy, A. Y. (2016). Fikri mülkiyet haklarının ihracat gelirleri üzerindeki etkisi. International Journal of Human Sciences, 13(1), 798-808. doi:10.14687/ijhs.v13i1.3599

Tablo 1'de en yüksek durağanlık mertebesinin tüm değişkenler için $\mathrm{I}(1)\left(\mathrm{d}_{\max }=1\right)$ olarak gerçekleştiği görülmektedir. Ayrıca VAR modellerinin gecikme uzunluğunun belirlenmesinde bilgi kriterlerine göre Tablo 2,3,4 ve 5'ten elde edilen sonuçlar tek tek sinanmış ve tüm modellerde gecikme uzunluğu $k=5$ olarak bulunmuştur. Diğer yandan İhracat ve patent değişkenini içeren modelde otokorelasyon problemini gidermek için $\mathrm{k}=6$ olarak analize dahil edilmiştir. Bu itibarla nedensellik ilişkisini test etmek için çalışmada VAR (6) modellerinin kullanılmasına karar verilmiştir.

VAR (6) modelleri için diagnostik test sonuçlanı Tablo 6 ve 7' de verilmiştir.

Tablo 6: VAR Modellerine Ait Diagnostik Test Sonuçları

\begin{tabular}{|c|c|c|c|c|c|c|c|}
\hline \multirow[t]{2}{*}{ Denklemler } & \multicolumn{3}{|l|}{ J-B Testi } & \multicolumn{3}{|l|}{ White Testi } & \multirow[t]{2}{*}{$\begin{array}{l}\text { CUSUM } \\
\text { Test }\end{array}$} \\
\hline & Jarque-Bera & df & Prob. & Chi-sq & df & Prob. & \\
\hline$\dot{I} H R-T A S$ & 21.68910 & 4 & 0.0002 & 75.29011 & 72 & 0.3724 & içinde \\
\hline$\dot{I} H R-F A Y$ & 9.089806 & 4 & 0.0589 & 64.52165 & 72 & 0.7224 & içinde \\
\hline$\dot{I H R}-M A R$ & 13.11125 & 4 & 0.0107 & 79.25177 & 72 & 0.2610 & içinde \\
\hline$\dot{I} H R-P A T$ & 11.55952 & 4 & 0.0209 & 97.16076 & 84 & 0.1544 & içinde \\
\hline
\end{tabular}

*\%1 Seviyesinde anlaml, $* * \% 5$ Seviyesinde anlamlı, ***\%10 Seviyesinde anlamlı

Tablo 6'ya yer alan diagnostik test sonuçlarını kontrol ettiğimizde kısmen normallik varsayımı dışında güvenirliliği ihlal eden sonuçların olmadığını söyleyebiliriz. Tahmin edilen VAR(6) diagnostik sonuçlarında White testinde değişen varyansın olmadığı sonucuna ulaşılmıştır. VAR istikrarllık testinde AR karakteristik ters polinom köklerinin birim çember içerisinde olduğu hem CUSUM hem de CUSUM kare testleriyle birim köklerin hiçbirinin çember dışında olmadığ1 sonucuna ulaşılmıstır.

Ayrıca Tablo 7’ de Autocorrelation-LM test sonuçlarında tüm denklemlerde yüzde 5 anlamlılık düzeyinde hata terimlerinin otokorelasyon içermediği görülmektedir.

Tablo 7: VAR Modellerine Ait Otokorelasyon Test Sonuçları

\begin{tabular}{|c|c|c|c|c|c|c|c|c|}
\cline { 2 - 9 } \multicolumn{1}{c|}{} & \multicolumn{2}{c}{ IHR-TAS } & \multicolumn{2}{c}{ IHR-FAY } & \multicolumn{1}{c|}{ IHR-MAR } & \multicolumn{2}{c|}{ IHR-P $A T$} \\
\hline Lags & LM-Stat & Prob & LM-Stat & Prob & LM-Stat & Prob & LM-Stat & Prob \\
\hline 1 & 2.892512 & 0.5760 & 0.913916 & 0.9226 & 4.175857 & 0.3827 & 4.377684 & 0.3573 \\
\hline 2 & 2.173768 & 0.7038 & 0.933984 & 0.9196 & 2.619347 & 0.6234 & 8.626373 & 0.0711 \\
\hline 3 & 1.447246 & 0.8359 & 1.064285 & 0.8999 & 4.669918 & 0.3229 & 2.849317 & 0.5834 \\
\hline 4 & 1.751508 & 0.7813 & 1.179849 & 0.8814 & 0.958947 & 0.9160 & 5.511368 & 0.2387 \\
\hline 5 & 3.346776 & 0.5016 & 6.348421 & 0.1746 & 2.035022 & 0.7293 & 4.504798 & 0.3420 \\
\hline 6 & 1.905953 & 0.7531 & 4.402757 & 0.3542 & 3.183152 & 0.5277 & 3.285315 & 0.5113 \\
\hline 7 & 3.233548 & 0.5195 & 1.363285 & 0.8506 & 2.745781 & 0.6012 & 3.055458 & 0.5486 \\
\hline 8 & 5.290393 & 0.2588 & 0.933985 & 0.9196 & 3.866471 & 0.4244 & 1.357773 & 0.8515 \\
\hline 9 & 5.572510 & 0.2334 & 7.759940 & 0.1008 & 6.417329 & 0.1701 & 7.649169 & 0.1053 \\
\hline 10 & 6.108613 & 0.1912 & 5.818651 & 0.2131 & 1.007475 & 0.9087 & 3.820956 & 0.4308 \\
\hline 11 & 5.823472 & 0.2127 & 3.738395 & 0.4426 & 5.550260 & 0.2353 & 5.204524 & 0.2669 \\
\hline
\end{tabular}

$* \% 1$ Seviyesinde anlaml, $* * \% 5$ Seviyesinde anlaml, $* * * \% 10$ Seviyesinde anlamlı 
Durmuşkaya, S., \& Ersoy, A. Y. (2016). Fikri mülkiyet haklarının ihracat gelirleri üzerindeki etkisi. International Journal of Human Sciences, 13(1), 798-808. doi:10.14687/ijhs.v13i1.3599

Yapılan diagnostik test sonuçlarına göre $\operatorname{VAR}(6)$ modenin tüm değişkenler için istikrarlı olduğuna karar verilmiştir. Ancak sadece patent değişkeninin yer aldığı model VAR(7) olarak istikrarlı sonuçlar vermiştir. Buradan hareketle yapılan Toda-Yamamoto nedensellik test sonuçları Tablo 8'de yer almaktadır.

Tablo 8: Toda-Yamamoto Test Sonuçları

\begin{tabular}{|c|c|c|c|c|}
\hline Bağımsız Değişken & Bağıml Değişken & Chi-sq & df & Prob. \\
\hline İHR & TAS & 9.999557 & 6 & 0.1247 \\
\hline TAS & İHR & 46.65976 & 6 & $0.0000^{*}$ \\
\hline İHR & FAY & 2.660938 & 6 & 0.8500 \\
\hline FAY & IHR & 23.51198 & 6 & $0.0006^{*}$ \\
\hline IHR & MAR & 1.099 .788 & 6 & $0.0884^{* * *}$ \\
\hline MAR & İHR & 1.954 .185 & 6 & $0.0033^{*}$ \\
\hline IHR & PAT & 29.14266 & 7 & $0.0001^{*}$ \\
\hline PAT & IHHR & 20.95380 & 7 & $0.0038^{*}$ \\
\hline
\end{tabular}

*\%1 Seviyesinde anlaml, $* * 05$ Seviyesinde anlaml, $* * * \% 10$ Seviyesinde anlamlı

Tablo 8'de yer alan sonuçlar incelendiğinde, ihracat tutarı ve tasarım başvuruları arasında \%1 anlam düzeyinde tasarım başvurularından ihracat tutarına doğru tek yönlü bir nedensellik ilişkisi bulunmuştur.

Aynı şekilde faydalı model ile ihracat tutarı arasında da \%1 anlam düzeyinde faydalı model başvurularından ihracat tutarına doğru tek yönlü bir nedensellik ilişkisi bulunmuştur. Bu durum tasarım başvuruları ve faydalı model başvurularında yaşanacak artışların ihracat tutarında da bir artışa neden olacağı şeklinde yorumlanabilir.

Diğer yandan marka başvuruları ve patent başvuruları ile ihracat tutarı arasında \%1 ve $\% 10$ anlam düzeyinde çift yönlü nedensellik ilişkisi bulunmuştur. Tablo 8 incelendiğinde ihracatın da \%10 anlam düzeyinde marka başvuruları üzerinde etkili olduğu görülecektir. Ancak ihracat ve patent başvuruları arasındaki nedensellik ilişkisi \%1 anlam düzeyinde çift yönlüdür. Bu durum hem ihracat tutarının marka başvurularını etkilediği hemde marka başvurularının ihracatı etkilediği anlamına gelmektedir.

\section{SONUÇ}

Çalışmamızda fikri mülkiyet unsurlarının ihracatla olan ilişkisi Türkiye özelinde incelenmiş olup, çalışmamızın ileride farklı ülke ve ülke grupları için yapılabilecek bu tarz çalışmalara 1şık tutacağı söylenebilir. Çalışmamızda fikri mülkiyet unsurları endüstriyel tasarım, faydalı model, marka ve patent başvuru sayıları olarak ele alınmış olup bu unsurların her biri ile ihracat arasında anlamlı bir ilişki bulunmuştur. Gerçekleştirdiğimiz ekonometrik analizin sonuçları göstermektedir ki; fikri mülkiyet unsurlarının gelişimi ile ihracattaki artış arasında önemli bir ilişki vardır.

Ekonomik çabaların siyasi olgularla olan ilişkisi göz ardı edilemeyeceğine göre, fikri mülkiyet unsurlarındaki gelişimin gerek ekonomik gerekse siyasi kurumlar tarafindan desteklenmeye muhtaç olduğu açıktır. Ülkemizde özellikle son dönemde Ar-Ge faaliyetlerinin öneminin kavrandığ1 ve bu faaliyetlerin desteklenmesine yönelik politikalar oluşturulmaya çalışıldığı gözlenmektedir. Ar-Ge faaliyetlerinin desteklenmesine yönelik olarak kurulan Teknoloji Geliştirme Bölgeleri bu kapsamda ele alınmalıdır. Ar-Ge faaliyetleri sonucunda olgunlaşacak olan sınai fikri mülkiyet unsurlarının geliştirilmesi ve yaygınlaştırılması için özellikle beşeri sermaye faktörüne yapılacak yatırımlar da büyük önem arz etmektedir. Bu bağlamda ülkemizde Ar-Ge'ye dayalı tekno girişimlerin önünün açlması ve Ar-Ge personeli yetiştirilmesi uluslararası rekabette yer alabilmek adına elzemdir. 
Gerçekleştirdiğimiz analiz çerçevesinde ortaya koyduğumuz sonuçlar göstermektedir ki ülkemiz ihracatının arttırabilmesi için fikri mülkiyet unsurlarının geliştirilmesi gerekmektedir. Bu da Ar-Ge potansiyelinin genişletilmesi ile mümkün olabilecektir. Ülkemizde Ar-Ge'ye dayalı fikri mülkiyet unsurlarının teşvik edilmesi ve gerek merkezi gerekse yerel yönetimler tarafindan desteklenmesi ile bölgesel ve ulusal ölçeklerde bir büyüme ivmesi sağlanacaktır.

\section{KAYNAKLAR}

Akar, C. (2008) Hisse Senedi Fiyatlarıyla Yabancı İşlem Hacmi Arasında nedensellik: TodaYamamoto Yaklaşımı, Mufad Journal, Sayı 37, Ocak

Altıntaş, H. (2013) Türkiye'de Petrol Fiyatlanı, İhracat ve Reel Döviz Kuru İlişkisi: Ardl Sınır Testi Yaklaşımı ve Dinamik Nedensellik Analizi, Uluslararası Yönetim İktisat ve Issletme Dergisi, Cilt 9, Say1 19

Bozkurt K. (2008), Türk İmalat Sanayiinde Teknolojik Gelişme ve İhracat Performansı, Finans Politik ve Ekonomik Yorumlar, Cilt 45 Say1.522

Chen Y. Puttitanun T. (2005), Intellectual Property Rights And Innovation In Developing Countries, Journal of Development Economics Vol.78

Göçer İ. (2013), Ar- Ge Harcamalarının Yüksek Teknolojili Ürün İhracatı , Dış Ticaret Dengesi ve Ekonomik Büyüme Üzerindeki Etkileri, Maliye Dergisi sayı.165

Gould, D., Gruben W. (1996), The Role Of Intellectual Property Rights In Economic Growth, Journal of Development Economics Vol.48, p.323-350

http://www.wipo.int/about-ip/en/ (Erişim Tarihi: 04.05.2015)

Kılıç S., Çınar R. (2014), Yerel Tekstil Ve Hazır Giyim İşletmelerinin Orijinal Marka Üretim Düzeyi ve İhracat Performanslarında Orijinal Tasarım Üretiminin Rolü: Çorum Tekstil Sektörü'ndeki İşletmelere Yönelik Bir Uygulama, H.Ü. İktisadi ve İdari Bilimler Fakültesi Dergisi, Cilt 32, Say1 2, s.165-194

Montobbio F., Rampa F. (2005), The Impact of Technology and Structural Change on Export Performance in Nine Developing Countries, World Development Vol.33 (4) p.527-547

Özer M., Çiftçi N.(2009), Ar-Ge Harcamaları ve İhracat İlişkisi: OECD Ülkeleri Panel Veri Analizi Dumlupınar Üniv. Sos. Bil. Dergisi sayı.29, Nisan

Park W. ve. Lippoldt D., (2004), International Licensing and the Strengthening of Intellectual Property Rights in Developing Countries, OECD Trade Policy Papers 10, OECD Publishing.

Schneider, P. (2005), International trade, economic growth and intellectual property rights : A panel data study of developed and developing countries, Journal of Development Economics Vol.78, p.529-547

Segerstrom, P. (1991), Innovation, Imitation and Economic Growth, Journal of Political Economy, University of Chicago Press, Vol. 99(4), p. 807-827, August

Seyoum, B. (1996), The Impact of Intellectual Property Rights on Foreign Direct Investment, The Colombia Journal of $W$ orld Business,

Toda, H.Y. ve Yamamoto, T. (1995) Statistical Inference in Vector Autoregressions with Possibly Integrated Process, Journal of Econometrics Vol,66

Uzay N., Demir M., Yıldırım E. (2012) İhracat Performansı Açısından Teknolojik Yeniliğin Önemi: Türkiye İmalat Sanayi Örneği, Doğus Üniversitesi Dergisi sayı.13 (1) s.147-160

Yıldırım E., Kesikoğlu F. (2012), Ar-Ge Harcamaları ile İhracat Arasındaki Nedensellik İlişkileri: Türkiye Örneğinde Panel Nedensellik Testi Kanıtlan, Marmara Üniversitesi İ.I.B.F Dergisi 


\section{Extended English Abstract}

The difference of wealth between developing and developed countries is suggested to be occurred due to the economic and social institutes founded besides run. Economic order certainly is not adequate to obtain economic welfare besides political factors are required for manufacturing structure. The most important qualification of capital system -being the major approach in the West since the industry revolution- is probably guaranteeing the freehold. The concept of property in the production context here is supposed to be related with industrial and intellectual property elements. Increasing in production may be provided by convincing the individuals about their rights. So that; they earn as much as they can generate.

Intellectual property is benefiting of inventions, literary and artworks, symbols, names, figures and designings in trade (WIPO: 2014). As a concept; intellectual properties include industrial and literary properties. While intellectual properties interest in utility models, designs, trademarks and geographical indications literary properties are related with art, literature and their publication rights. Because industrial development is considered to be a substantial element to ensure fair competition in the markets; supporting and developing the industrial properties should clearly be regarded. Intellectual property concept is mentioned in 15th century in the continental Europe on the contrary of Turkey where the concept is questioned in early 1800s under Ottoman rule. However; Turkey has a considerable progress about the issue since 1996 due to the studies for EU compliance.

The causality relation between exporting amount and the application numbers for industrial designs, utility models, trademarks and patent is examined in the study by using 75 months data set from January 2009 to March 2015. Here; the selection of the mentioned period is related with the unavailability of the appropriate data belonged to the former months. The data about exporting amounts are acquired from the official web site of Turkish Statistical Institute while the application numbers for industrial designs, utility models, trademarks and patents are obtained via Turkish Patent Institute's web site.

The mentioned data acquired from Turkish Patent Institute indicates the total number of applications both domestic and international characterized. The fundamental reason here is to differentiate the effects of native and foreign investors' activities in Turkey.

Toda-Yamamoto Causality Test is run in the study via E-views 7.0 software to reveal the causality relation between the variables in the context of obtaining accurate results for the analysis of smaller sample sets.

The mentioned method uses modified Wald test which is benefited to find out the significance level of a VAR model's parameters. According to Toda and Yamamoto; the modified Wald test can be applied for the series in any combination of I(0), I(1) or I(2) cases (Altıntaş, 2013: 13). The important factors for Toda-Yamamoto Test is suggested to be the "lagging length" (k) and "the biggest range of stability level" $\left(\mathrm{d}_{\max }\right)$ of the examined series. Hence; Toda-Yamamoto Test can be run after the mentioned values are determined by a VAR model in $\left(k+d_{\max }\right)$ size.

The coefficients of the terms added to the model later are ignored. The integration level $\left(\mathrm{d}_{\max }\right)$ should not exceed the substant level of VAR model (k) (Akar, 2008: 189). So that; the 8 VAR models used in the study are built basing on the model shown in Equation 1:

$\dot{I} H R_{t}=\alpha_{10}+\sum_{i=1}^{k} \alpha_{1 i} T A S_{t-i}+\sum_{i=1}^{k} \beta_{1 i} \dot{I} H R_{t-i}+\sum_{j=k+1}^{d m a x} \delta_{1 i} T A S_{t-i}+\sum_{j=k+1}^{d m a x} \lambda_{1 i} \mathbb{I} H R_{t-i}+\varepsilon_{1 t}$

The results calculated via the analyses by the VAR models set are indicated below in Table 1 . 
Durmuşkaya, S., \& Ersoy, A. Y. (2016). Fikri mülkiyet haklarının ihracat gelirleri üzerindeki etkisi. International Journal of Human Sciences, 13(1), 798-808. doi:10.14687/ijhs.v13i1.3599

Table 1: Toda-Yamamoto Test Results

\begin{tabular}{|l|l|l|l|l|}
\hline Variable & $\begin{array}{l}\text { Dependent } \\
\text { Variable }\end{array}$ & Chi-sq & df & Prob. \\
\hline İHR & TAS & 9.999557 & 6 & 0.1247 \\
\hline TAS & İHR & 46.65976 & 6 & $0.0000^{*}$ \\
\hline İHR & FAY & 2.660938 & 6 & 0.8500 \\
\hline FAY & İHR & 23.51198 & 6 & $0.0006^{*}$ \\
\hline İHR & MAR & 1.099 .788 & 6 & $0.0884^{* * *}$ \\
\hline MAR & İHR & 1.954 .185 & 6 & $0.0033^{*}$ \\
\hline İHR & PAT & 29.14266 & 7 & $0.0001^{*}$ \\
\hline PAT & İHR & 20.95380 & 7 & $0.0038^{*}$ \\
\hline
\end{tabular}

* Significant in 1\% level, ** Significant in 5\% level, *** Significant in 10\% level

Due to the analyses held; one direction causality relationship is revealed in $1 \%$ significance level from the exporting amount to design applications.

Similarly; another one direction causality relationship is revealed in 1\% significance level between the number of applications for utility models and the exporting amount in the mentioned sequence. So that the number of applications for design and utility models is

Furthermore two direction causality relations are revealed between the application numbers for trademarks \& patents and exporting amount in 1\% and 10\% significance levels. Besides; exporting amount is suggested to have a causality affect on trademark applications in $10 \%$ significance level. But exporting amount and patent application numbers have a two-direction causality effect in 1\% significance level meaning that both sides affect the other significantly.

\section{RESULTS}

In the study; the relationship between intellectual properties' components and exporting amount is analyzed in Turkey context. The results acquired are suggested to be benefited in similar studies for different countries and country groups. Here the components are application numbers for industrial designs, utility models, trademarks and patents besides it is revealed that each of them has significant relations with export. The econometric analysis held indicates that the development of intellectual properties has a relation with the increase in exporting amount.

As the economic efforts are related with politic issues; the development of intellectual properties' components are to be supported by economic and politic institutions. The importance of R\&D activities has been seen and they are supported politically in the recents years so that Technology Development Zones to support R\&D avtivities are founded. The development of the intellectual property components matured by $\mathrm{R} \& \mathrm{D}$ activities are considered to be substantial hence the future investment on human capital factor is essential.

The analysis held indicates that the components of intellectual properties are to be developed to increase the exporting amount of Turkey which is suggested to bepossible by the expanding of the $R \& D$ potential. Supporting the intellectual property components based on $R \& D$ activities not only by local but also central administration can obtain the increase in national development. 